\title{
Chlorambucil induced chromosome damage in juvenile chronic arthritis
}

\author{
R G PALMER, S VARONOS, C J DORÉ, A M DENMAN, AND B M ANSELL \\ Divisions of Rheumatology and Computing and Statistics, Clinical Research Centre, Northwick Park \\ Hospital, Harrow
}

SUMMARY Sister chromatid exchanges, a sensitive measure of chromosome damage, were counted in peripheral blood lymphocytes from 23 patients with juvenile chronic arthritis receiving long term, low dose chlorambucil treatment. Thirty five patients with juvenile chronic arthritis who had not been treated with cytotoxic drugs served as controls. All of the treated patients have cells with abnormal sister chromatid exchange frequencies. Damage is related to the daily dose and may, in part, be determined by the duration of treatment. Sister chromatid exchanges from nine patients who had received chlorambucil at some time in the past remained high for at least five months after stopping the drug. Long term follow up will determine whether sister chromatid exchange analysis can help predict those most at risk of drug induced malignancies.

Cytotoxic drugs are used as immunosuppressive treatment for complications of juvenile chronic arthritis that do not respond to other forms of treatment. Amyloidosis is usually life threatening, but if the disease can be controlled by chlorambucil, life expectancy is improved. ${ }^{1}$ Other complications such as uveitis, which are associated with a high morbidity but low mortality, may also improve with chlorambucil. ${ }^{2}$ Unfortunately these children are at risk of developing drug induced malignancies, ${ }^{34}$ which are almost exclusively acute leukaemias, and which may develop many years after stopping cytotoxic drugs. ${ }^{5}$

The concern that has been expressed about the use of chlorambucil for childhood nephrosis ${ }^{6}$ applies equally to its use for juvenile chronic arthritis. It is therefore particularly important that the chromosome damaging effects of this drug are closely monitored. The conventional method of assessment in man is by detection of chromosome aberrations in peripheral blood lymphocyes. Using this technique, it has been claimed that long term, low dose chlorambucil treatment for adult patients with uveitis induces negligible chromosomal damage. ${ }^{7}$ It is now clear, however, that sister chromatid exchange is a much more sensitive method for assessing the genotoxic effects of chlorambucil ${ }^{8}$ and that in adult patients with non-malignant diseases treated for many months with this drug, the extent of chromosome damage is dose dependent and cumulative ${ }^{8}$ This report details the observations on sister chromatid exchange frequencies in children with juvenile chronic arthritis who have received long term, continuous chlorambucil treatment.

\section{Patients and methods}

Patients. Twenty three patients with juvenile chronic arthritis-were receiving chlorambucil at the time of the study. Eighteen were being treated for renal amyloidosis, three for uveitis, and two for persistent systemic disease activity. Nine patients had received chlorambucil at some time in the past. Thirty five patients with juvenile chronic arthritis who had never received cytotoxic drugs served as controls. Details of patient age, sex, type of onset of disease, and its duration and activity are given in Table 1 . All patients fulfilled recognised criteria for this disease ${ }^{9}$ and developed their disease before the age of 16 years. With few exceptions, chlorambucil was begun before the age of 16 years. Since many patients had been treated for several years, however, their ages at the time of the study were sometimes greater than 20 years (Table 1 ). The daily intake of chlorambucil at the time of study ranged from 0.01 to $0.16 \mathrm{mg} / \mathrm{kg}$ and the duration of continuous treatment ranged from one to 177 months (Table 2). Most patients received the drug every day, although some had alternate day or twice weekly treatment. For ease of data analysis, the daily dose equivalents of these 


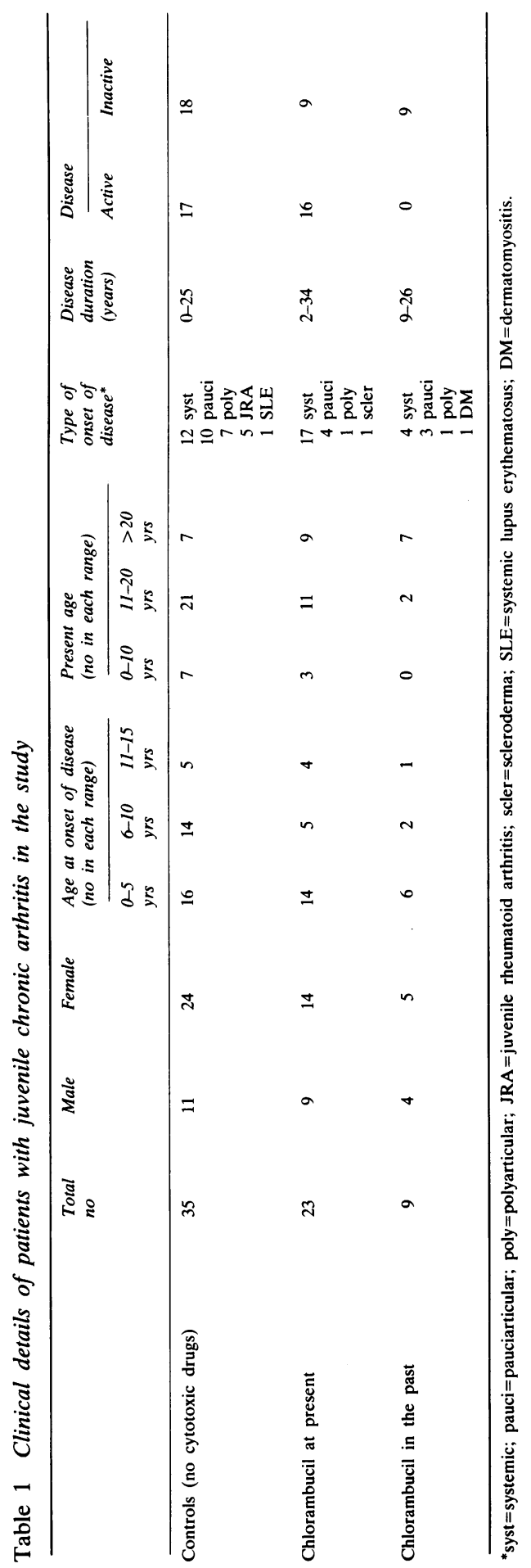

patients have been calculated. Many were also being treated with systemic steroids.

Sister chromatid exchange estimation. The whole blood technique used for prepararing metaphase spreads that show sister chromatid exchanges has already been published. ${ }^{8}$ Permanent preparations were made by the Goto variation ${ }^{10}$ of the fluorescence plus giemsa technique of Perry and Wolff. ${ }^{11}$ The sister chromatid exchanges from 20 second division metaphases from each subject were counted.

\section{Results}

A typical metaphase spread showing sister chromatid exchanges is given in Fig. 1. The sister chromatid exchange frequencies of the controls (Fig. 2) do not differ from those of healthy adult controls (adult data already published). ${ }^{8}$ There is no significant relation between sister chromatid exchange frequencies and the type of onset of disease, its duration, or its activity at the time of analysis.

Chlorambucil induces a highly significant increase in sister chromatid exchanges in the treated patients compared with the controls $(\mathrm{P}<0 \cdot 001)$ (Fig. 2). The sister chromatid exchange data and details of chlorambucil treatment are detailed in Table 2. The $95 \%$ confidence limits for the mean sister chromatid exchange per metaphase of the untreated patients are 4.6 to 8.3 and the mean frequencies of 20 of the 23 treated patients are outside this range.

Some treated patients have cells with sister chromatid exchanges that are unexpectedly high in comparison with the other cells of the same patient. The abnormality score that has been devised by us ${ }^{8}$ is a measure of both the number of cells with high sister chromatid exchanges and the extent of this process in these cells. We have considered that cells with counts above 15 were likely to be abnormal. Fifteen was subtracted from each abnormal count and the logarithm taken of the remainder. A patient's total abnormality score was the sum of these logged scores. ${ }^{8}$ When this sensitive scoring system is used only one of the 35 control patients has a positive abnormality score. In contrast all 23 treated patients have a positive score.

Multiple regression analysis showed that excessive sister chromatid exchanges (expressed as the abnormality score) are closely related to the present daily dose $(\mathrm{P}<0.005)$, but not to the total past dose $(\mathrm{P}=0 \cdot 8)$ or duration of treatment $(\mathrm{P}=0 \cdot 5)$. These results may be distorted, however, by the fact that the present daily dose of these patients decreases as the treatment period becomes longer $(\mathrm{P}<0 \cdot 02$, data not shown). This may be masking the effect of 
1010 Palmer, Varonos, Doré, Denman, and Ansell

Table 2 Patients with juvenile chronic arthritis on chlorambucil-sister chromatid exchange (SCE) frequencies and treatment

\begin{tabular}{|c|c|c|c|c|c|}
\hline No & $\begin{array}{l}\text { Present dose } \\
(\mathrm{mg} / \mathrm{kg})^{*}\end{array}$ & $\begin{array}{l}\text { Total past dose } \\
(\mathrm{mg} / \mathrm{kg}) \dagger\end{array}$ & $\begin{array}{l}\text { Duration of } \\
\text { treatment (months) }\end{array}$ & $\begin{array}{l}\text { Mean SCE per } \\
\text { metaphase }\end{array}$ & $\begin{array}{l}\text { Abnormality } \\
\text { score }\end{array}$ \\
\hline 1 & $0 \cdot 07$ & 131 & 62 & $12 \cdot 2$ & 1.4 \\
\hline 2 & 0.04 & 137 & 107 & 14.5 & $5 \cdot 0$ \\
\hline 3 & 0.04 & 213 & 177 & 14.8 & $7 \cdot 8$ \\
\hline 4 & 0.05 & 204 & 138 & $16 \cdot 4$ & $7 \cdot 8$ \\
\hline 5 & 0.01 & 88 & 96 & 7.9 & 1.0 \\
\hline 6 & $0 \cdot 10$ & 243 & 88 & $13 \cdot 8$ & 5.4 \\
\hline 7 & 0.08 & 22 & 8 & $16 \cdot 8$ & $9 \cdot 2$ \\
\hline 8 & $0 \cdot 11$ & 293 & 86 & 14.8 & $5 \cdot 0$ \\
\hline 9 & $0 \cdot 16$ & 71 & $\begin{array}{l}00 \\
18\end{array}$ & 15.6 & $6 \cdot 2$ \\
\hline 10 & $0 \cdot 10$ & 22 & 5 & 16.0 & $7 \cdot 2$ \\
\hline 11 & 0.03 & 72 & 38 & 9.5 & 0.8 \\
\hline 12 & 0.02 & 82 & 68 & 11.9 & 3.4 \\
\hline 13 & 0.06 & 83 & 29 & $15 \cdot 6$ & $6 \cdot 0$ \\
\hline 14 & 0.02 & $\begin{array}{l}03 \\
91\end{array}$ & 108 & $10 \cdot 5$ & $2 \cdot 8$ \\
\hline 15 & 0.02 & 16 & 12 & 9.7 & 0.4 \\
\hline 16 & $0 \cdot 11$ & 3 & 1 & 13.8 & $3 \cdot 2$ \\
\hline 17 & 0.01 & 127 & 169 & $7 \cdot 3$ & 1.6 \\
\hline 18 & $0 \cdot 10$ & 7 & 2 & $17 \cdot 2$ & 9.8 \\
\hline 19 & 0.04 & 207 & 113 & 12.8 & $5 \cdot 0$ \\
\hline 20 & 0.02 & $\begin{array}{r}201 \\
88\end{array}$ & 90 & $\begin{array}{l}11.0 \\
11.9\end{array}$ & 3.8 \\
\hline 21 & 0.02 & $\begin{array}{l}00 \\
35\end{array}$ & 26 & $14 \cdot 1$ & $\begin{array}{l}3.0 \\
4.0\end{array}$ \\
\hline 22 & $0 \cdot 10$ & 60 & 21 & $18 \cdot 1$ & 9.4 \\
\hline 23 & 0.02 & 66 & 71 & $7 \cdot 1$ & 1.0 \\
\hline
\end{tabular}

*Present weight: taverage weight during treatment period; because of large variations in body weight between individuals drug doses are given in mg/kg only: $\ddagger$ łeometric mean.

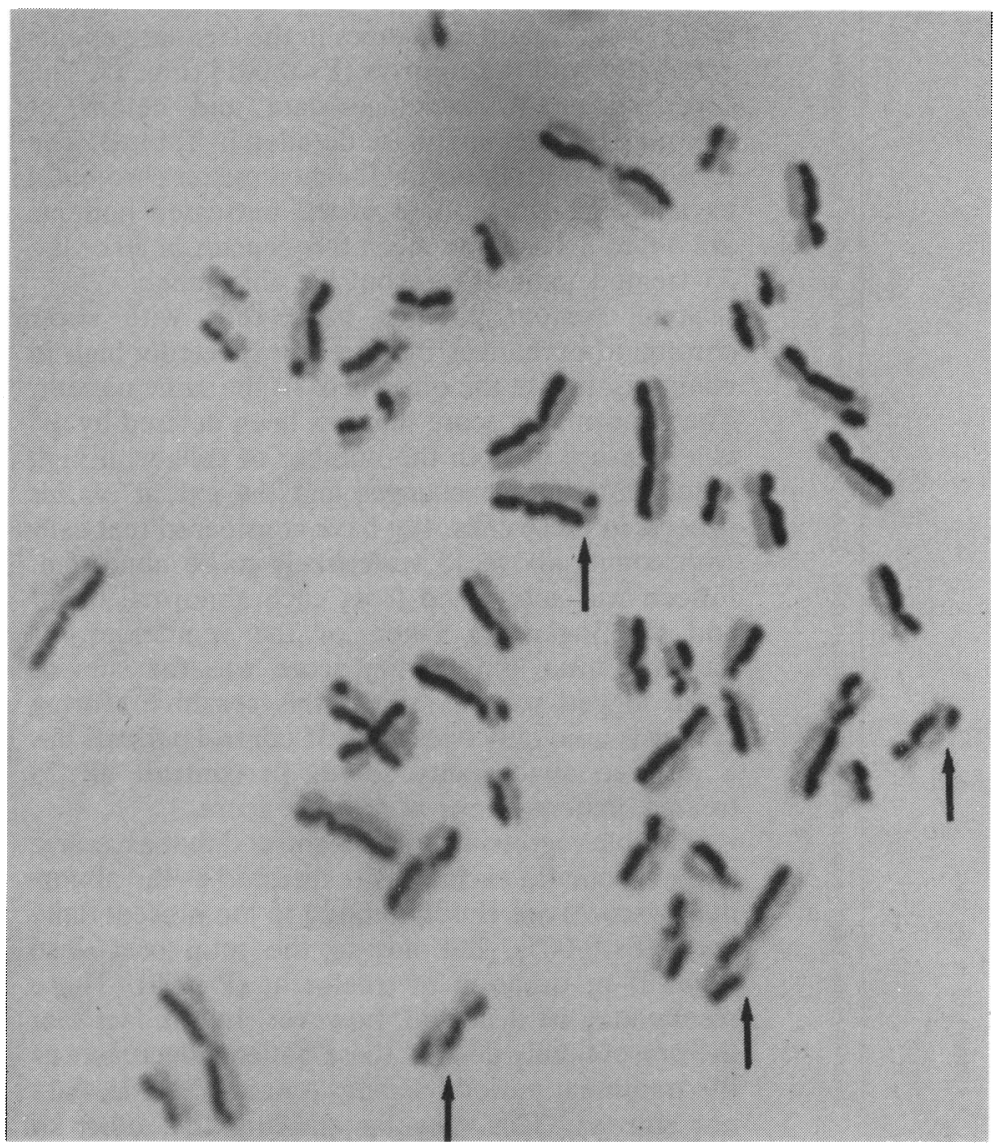

Fig. 1 Examples of sister chromatid exchanges. One chromatid of each chromosome is dark and the identical sister chromatid is pale. Exchange between sister chromatids is easily visible (arrows). 


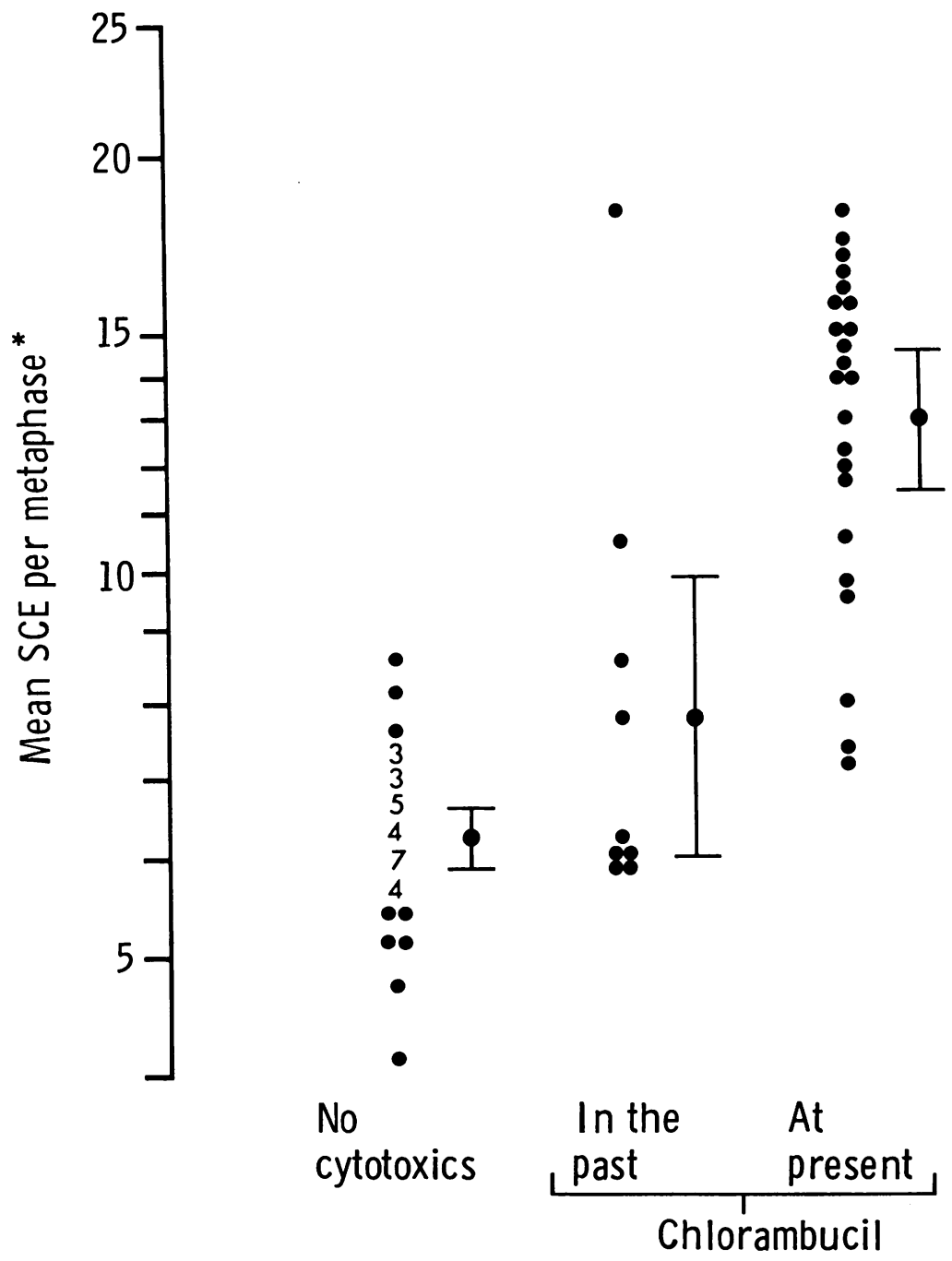

Fig. 2 Sister chromatid exchanges of juvenile chronic arthritis patients on chlorambucil at present and of those who received chlorambucil in the past are higher than those who have never received this drug $(P<0 \cdot 001$ and $P<0.01$ respectively).

(Student's $t$ test with $\log$ transformation of sister chromatid exchange (SCE) count +1 ). ${ }^{*}$ Geometric mean. Vertical bars $=$ mean and $95 \%$ confidence intervals for the mean.

duration of treatment on sister chromatid exchange frequencies. The natural increase in body weight of children may account for this finding. For the adult patients already reported by us, ${ }^{8}$ the daily dose did not change appreciably during the treatment period. If those children who are receiving less than $0 \cdot 06$ $\mathrm{mg} / \mathrm{kg}$ of chlorambucil per day are analysed separately, then the bias caused by the reducing dose is removed. The drug schedules of this restricted group are similar to those of the adult patients. The effect of duration of treatment and total past dose on sister chromatid exchanges then becomes apparent. For these 13 patients the extent of chromosome damage, as measured by the abnormality score, is related to both the present daily dose in $\mathrm{mg} / \mathrm{kg}(\mathrm{P}<0.005)$ and the total length of treatment 
Table 3 Patients with juvenile chronic arthritis given chlorambucil in the past: sister chromatid exchange (SCE) frequencies and treatment

\begin{tabular}{|c|c|c|c|c|c|}
\hline No & $\begin{array}{l}\text { Total past } \\
\text { dose }(\mathrm{mg} / \mathrm{kg})\end{array}$ & $\begin{array}{l}\text { Duration of } \\
\text { past treatment } \\
\text { (months) }\end{array}$ & $\begin{array}{l}\text { Months since } \\
\text { treatment stopped }\end{array}$ & $\begin{array}{l}\text { Mean SCE } \\
\text { per metaphase* }\end{array}$ & $\begin{array}{l}\text { Abnormality } \\
\text { score }\end{array}$ \\
\hline 1 & 49 & 18 & 41 & 5.9 & 0 \\
\hline 2 & 64 & 55 & 65 & $6 \cdot 1$ & 0 \\
\hline 3 & 12 & 11 & 36 & $6 \cdot 2$ & 0 \\
\hline 4 & 76 & 46 & 87 & $6 \cdot 1$ & 0 \\
\hline 5 & 108 & 132 & 5 & 8.3 & 3.6 \\
\hline 6 & 117 & 100 & 39 & 5.9 & 0 \\
\hline 7 & 215 & 113 & 3 & $10 \cdot 5$ & 3.4 \\
\hline 8 & 100 & 101 & 2 & $7 \cdot 7$ & 1.0 \\
\hline 9 & 117 & 80 & 3 & $17 \cdot 6$ & 11.4 \\
\hline
\end{tabular}

*Geometric mean.

in months $(\mathrm{P}<0 \cdot 05)$. Similarly, the total past dose is also important in determining sister chromatid exchange frequencies $(\mathrm{P}<0 \cdot 05)$.

The sister chromatid exchanges of two patients have been assessed on two occasions separated by a year or more. In each case, the sister chromatid exchanges increased as the treatment period lengthened: for one patient the mean frequency was $9 \cdot 5$ after 38 months of treatment increasing to 12.5 some 12 months later, and for the other patient the mean frequency was 13.8 after 88 months of treatment increasing to 15.2 some 14 months later. The daily doses of chlorambucil did not change between the two assessments.

Nine patients had received chlorambucil in the past but were not receiving this drug at the time of the study (Tables 1 and 3, Fig. 2). Their sister chromatid exchanges are higher than those of the control group $(\mathrm{P}<0 \cdot 01)$, and although abnormal frequencies were present in one patient five months after stopping treatment, they were normal in those who had been off treatment for 36 months or more.

\section{Discussion}

These observations show that sister chromatid exchange analysis is a very sensitive measure of chromosome damage induced by chlorambucil used as immunosuppressive treatment for children with juvenile chronic arthritis. The extent of chromosome damage is closely related to the present daily dose, and although the analysis of the results is complicated by the drug regimens that are used for these patients, it is likely that the extent of chromosome damage is also determined by the total dose received or the duration of treatment. The sister chromatid exchanges of two patients who were studied twice increased with the duration of treatment. These observations suggest that chromosome damage induced by chlorambucil is cumulative, and that in some cells, damage is long lived and possibly permanent. They are consistent with our previously reported observations on the genotoxic effects of chlorambucil in adult patients, ${ }^{8}$ and also with clinical studies on chlorambucil induced malignancies. The risk of developing leukaemia after treatment with this drug is related to the duration of treatment and total past intake in adult patients with rheumatic diseases ${ }^{12}$ and others with polycythaemica vera. ${ }^{13}$ Some patients develop chlorambucil induced leukaemias many months or years after stopping the drug ${ }^{5}$ suggesting that the damage to cells that undergo malignant transformation is long lived and possibly permanent. The in vivo positive dose-response effect of chlorambucil that has been observed in our patients has also been shown in vitro. ${ }^{14}$

In general, the mean sister chromatid exchange frequencies of patients who have stopped chlorambucil are lower than those who are continuing treatment. It seems that frequencies can remain high for at least five months, but that they have returned to normal by 36 months. This longevity has not been previously reported; most workers have observed that sister chromatid exchanges are normal within days or weeks of stopping treatment. ${ }^{15}$ Published reports, however, generally concern patients with malignant diseases who have received intermittent short courses of multiple cytotoxic treatment. Our patients are very different: they have non-malignant disorders and have received continuous low dose treatment with one cytotoxic agent for many months and sometimes for many years. The long treatment periods of our patients may be determining the longevity of chromosomal lesions.

Sister chromatid exchange analysis is clearly a very sensitive measure of chromosome damage induced by chlorambucil: children who have received as little as $0.01 \mathrm{mg} / \mathrm{kg}$ per day (administered as an equivalent twice weekly dose) have abnormal 
frequencies. The conventional method of assessing chromosome damage using chromosome aberration frequencies does not detect the extensive chromosome damage induced by chlorambucil treatment that is evident when sister chromatid exchanges are analysed. ${ }^{7}$ By monitoring sister chromatid exchanges in these patients it may be possible to identify those who are most at risk of drug induced malignancy.

\section{References}

${ }^{1}$ Schnitzer TJ, Ansell BM. Amyloidosis in juvenile chronic polyarthritis. Arthritis Rheum 1977;20:245-52.

2 Mehra R, Moore TL, Catalano JD, et al. Chlorambucil in the treatment of iridocyclitis in juvenile rheumatoid arthritis. $J$ Rheumatol 1981;8:141-4.

${ }^{3}$ Buriot D, Prieur A-M, Lebranchu Y, et al. Leucemie aigue chez trois enfants atteints d'arthrite chronique juvenile traites par le chlorambucil. Arch Fr Pediatr 1979;36:592-8.

4 Palmer RG, Ansell BM. Acute leukaemia related to chlorambucil therapy for juvenile chronic arthritis. Clin Exp Rheumatol 1984;2:81-3.

5 Palmer RG, Denman AM. Malignancies induced by chlorambucil. Carcer Treat Rev 1984;11:121-9.

6 Anonymous. Chlorambucil for childhood nephrosis. $N$ Engl $J$ Med 1980;302:963-4.

7 Reeves BR, Pickup VL, Lawler SD et al. A chromosome study of patients with uveitis treated with chlorambucil. $\mathrm{Br}$ Med $\mathrm{J}$ 1975;iv:22-3.

${ }^{8}$ Palmer RG, Doré CJ, Denman AM. Chlorambucil-induced chromosome damage to human lymphocytes is dose-dependent and cumulative. Lancet 1984;i:246-9.

9 Munthe E, ed. In: The care of rheumatic children. EULAR Bulletin Monograph Series no 3, Basle: EULAR 1977:47-50.

10 Goto K, Meada S, Kano Y, et al. Factors involved in differential giemsa-staining of sister chromatids. Chromosoma 1978;66: 351-9.

11 Perry P, Wolff S. New giemsa method for the differential staining of sister chromatids. Nature 1974;251:156-8.

12 Kahn MF, Arlet J, Bloch-Michel H, et al. Leucemies aigues après traitement par agents cytotoxiques en rhumatologie. Nouv Presse Med 1979;8:1393-7.

${ }^{13}$ Berk PD, Goldberg JD, Siverstein MN, et al. Increased incidence of acute leukemia in polycythemia vera associated with chlorambucil therapy. $N$ Engl J Med 1981;304:441-7.

14 Solomon E, Bobrow M. Sister chromatid exchanges-a sensitive assay of agents damaging human chromosomes. Mutat Res 1975;30:273-8.

15 Raposa T. SCE and chemotherapy of non-cancerous and cancerous conditions. In: Sandberg AA, ed. Sister chromatid exchange. New York: A R Liss Inc, 1982:579-617.

Correspondence to Dr R G Palmer, Division of Rheumatology, Clinical Research Centre, Northwick Park Hospital, Harrow, Middlesex.

Received 7 June 1985 